\title{
Lessons for FCDO climate change programming in East Africa
}

\author{
Laura Bolton
}

IDS

5 May 2021

\section{Question}

What are the main lessons from the FCDO funded projects/research focusing on climate and weather in East Africa? (This could include but is not limited to different types of approaches and their influence on decision making e.g. co-creation).

\section{Contents}

1. Summary

2. Future climate for Africa (FCFA), East Africa region

3. FCFA across the whole of the African region

4. WISER learning event

5. References

The K4D helpdesk service provides brief summaries of current research, evidence, and lessons learned. Helpdesk reports are not rigorous or systematic reviews; they are intended to provide an introduction to the most important evidence related to a research question. They draw on a rapid desk-based review of published literature and consultation with subject specialists. 


\section{Summary}

This report mainly includes lessons on programming from Future Climate for Africa (FCFA), a research and development programme enhancing scientific knowledge and climate predictions. The original aim of the report was to look at FCDO climate projects across the region and this had to be scaled down for two reasons. Firstly it became apparent that there was an extensive amount of materials to look through from climate projects and secondly, a significant amount of time was needed to draw out lessons that were specifically useful for approaches and programming. This report started with FCFA which ended up taking the majority of the allocated resources.

Section 4 provides some top-level outcomes from a Weather and Climate Information Services for Africa (WISER) learning event. Further resources are needed to look further into lessons from the WISER programme and the Collaborative Adaptation Research Initiative in Africa and Asia (CARIAA). The findings in this report will help to shape a deeper and broader investigation of lessons for FCDO programming in applying climate research to policy and action in East Africa.

FCFA lessons published for the African region as a whole were more explicit and thought to be of use for the report and so included here.

Findings from FCFA in East Africa include:

- Iterative engagements with tea sector stakeholders in Kenya were noted to improve understanding of local scale vulnerabilities and helped stakeholders identify relevant adaptation options.

- A risk-screening tool (and accompanying workshop) was found to be more useful than a climate information fact sheet for relaying information from Rwanda's climate and environment fund (FONERWA). It highlighted the importance of getting the right information in the right format to meet user needs.

- Interviews with policy makers in Rwanda in 2014 found that most information users did not consider future climate model uncertainty.

- Work in Tanzania concluded the importance of designing approaches that are strongly informed by local considerations and are robust to uncertainty.

- Recommendations from Tanzania on making a trade-off between robustness and resources are to choose the right tool and approach to suit the scale of the decision.

- Experience in addressing flooding in Uganda found it was useful to translate modelling into management tools by combining the climate data with sanitation, infrastructure and socio-economic maps.

- An example of visual video story telling was found to be successful for farmers in Uganda to address the mismatch between the information provided and information needed.

- Worked with the Ugandan Ministry of Water and Environment (MWE) who were already developing catchment plans for Water Management Zones was a successful approach for information transmission.

Publications from FCFA with lessons from across Africa include:

- A manual advising on principles for good co-production. These include building trust, enhancing inclusivity, and keeping flexible.

- A guidance document on approaches to communicating climate uncertainties to decision makers. Recommendations include ensuring that visuals are presented by a credible 
expert and followed-up with support; and having narratives that suggest three possible futures rather than using the language of uncertainty. Communicating uncertainty should include a series of engagements and segment the target audience. Establishing a human connection with stakeholders is recommended.

- Interviews with project staff and a brief on collective learning are addressing how to get the most out of institutional learning to improve programming.

Discussion of learning outcomes within WISER acknowledge the value of institutional learning and sharing moving forward. Recommendations for programming include:

- Gender and disability inclusion should be explicitly included in plans and have resource allocation.

- Learning between and among projects needs to be planned and integrated into project activities.

- User feedback loops require dedicated human resources.

- Co-production was agreed as important and should be increased as much as possible.

\section{Future climate for Africa (FCFA), East Africa region}

FCFA is a research and development programme enhancing scientific knowledge and climate predictions. It is also piloting methods to ensure impact on development problems.

\section{Kenya}

FCFA work in Kenya is carried out by HyCRISTAL.

Iterative engagements with sector stakeholders in the Climate Information for Resilient Tea Production (Cl4Tea) project helped tailor information to their needs and incorporate their feedback to develop usable information. ${ }^{2}$ Climate models were used to analyse how temperature and rainfall thresholds may be exceeded in the future; stakeholders were provided with graphical and statistical information. ${ }^{3}$ The information was then combined with historical information to determine potential impacts. Iterative engagements were noted to have improved understanding of local scale vulnerabilities and helped stakeholders identify relevant adaptation options. ${ }^{4}$ The adaptation options were not further described on the FCFA website.

Other descriptions of HyCRISTAL work in Kenya did not include specific lessons from a climateperspective or evidence on how findings are influencing decision making.

\footnotetext{
${ }^{1}$ https://futureclimateafrica.org/project/hycristal/ Accessed 23.4.21

${ }^{2}$ https://futureclimateafrica.org/summary-of-fcfas-research-on-climate-change-in-kenya/ Accessed 23.4.2

3 This information was found in a project planning document rather than post-project description. https://futureclimateafrica.org/wp-content/uploads/2015/10/ci4tea_briefing-note_kenya-1.pdf
}

${ }^{4}$ https://futureclimateafrica.org/summary-of-fcfas-research-on-climate-change-in-kenya/ Accessed 23.4.21 


\section{Rwanda}

FCFA are work on developing capacity of Rwanda's climate and environment fund (FONERWA) and identified a need for climate impact information that could be communicated with the project developers after there was limited engagement with a climate information factsheet and workshop (Bouwer \& Araujo, 2020). This led to the development of a risk-screening tool with relevant information for developers (FONERWA, 2018).

The tool includes:

- How to identify where risks and mitigation measures need to receive more information in proposals.

- Standardised feedback for expert reviewers to deliver to project developers. It provides information on project funding processes.

- Detailed impacts and suitability maps for different crops and livestock.

- Explanation of thresholds.

- A climate risk checklist.

- How to identify potential climate smart practices to counter the negative effects of climate change.

It requires input of the best available climate data for the scale and type of project. The tool covers guidance for reviewers; guidance for project developers; a climate risk checklist; information specific to different crops and livestock, and advice on climate smart agriculture. A second workshop, using the risk-screening tool, was more effective than the workshop presenting the factsheet: "many of the participants were able to use the tool to better understand and relate to climate impacts, as a result, many believed the workshop was more interesting and valuable" (Bouwer \& Araujo, 2020, p2). Getting climate information into projects was "found to be more effective when detailing climate impacts with climate change information as context and not the other way around" (Bouwer \& Araujo, 2020, p2). This highlights the need for getting the right information in the right form to meet the end users need. The increase in project proposals incorporating climate risks was also supported by the emergence of local champions within FONERWA.

A report demonstrates the use of climate information in assessing adaptation needs and implementation in the tea and coffee sector in Rwanda (Watkiss, 2015a). It demonstrates the sequence of programming activities and where climate information should come within this, which was found to be a successful model. The report uses a different definition of 'adaptation deficit' that "recognises that it is not economically efficient to reduce the adaptation gap to zero" (p4) but rather that the existing adaptation gap is not optimal. Experience in Rwanda was that high-level screening of all agricultural sub-sectors helped focus and quickly identify areas that had large potential risks and where there were opportunities for mainstreaming. Future climate risks are particularly pertinent to tea and coffee which have a long payback period and long expected lifespan. Costs were compared for three types of adaptation activity identifying an early set of interventions. The implementation plan needed to be agreed by the relevant finance organisations and actors implementing on the ground (farm organisations and cooperatives). The programme design included a component for learning and evaluation including dissemination to the government. 
Interviews with policy-makers 5 in Rwanda in 2014 identified that the majority used qualitative narratives rather than quantitative projections (Watkiss, 2015b). They also use a variety of resources which can lead to inconsistency. Most information users did not consider future climate model uncertainty. They were interested in climate extremes as well as future trends and were more interested in the next 5-15 years than longer-term. The interviews identified a lack of historic observational and current risks making it harder to understand future projections. Interviewees reported lack of time and capacity for including climate information. Case studies ${ }^{6}$ within the same report highlight the importance of the correct entry point and windows of opportunity for climate information to be used in making sure risks are captured at an early stage of planning. The study found that better information is needed on adaptation links with hydrological information and analysis. Watkiss (2015b) concludes that understanding the context, existing decision-making approach, and intervention points are critical to the success of integration of medium- to long-term climate information. There is a need for "consistent and harmonised future climate projections for Rwanda that are country-specific, or for guidance on which external climate information sources to use and how to use them" (p3). More information is required on variability and extremes, and relevant hydro- and agrometeorological variables, particularly threshold levels. Intermediary organisations are needed to bridge the interface between science and practice.

\section{Tanzania}

FCFA research in Tanzania is carried out by UMFULA. ${ }^{7}$ UMFULA have applied a DecisionMaking under Uncertainty approach in studying the Rufiji River Basin. ${ }^{8}$ Tanzania is positioned between the major climate systems of Southern and Eastern Africa making predictions difficult. Results highlight the need for adaptive dam operational rules to deal with variable reservoir inflows.

UMFULA undertook an analysis of political economy to better understand institutional decision making. They have also looked at identifying climate needs, how to design capacity building and how seasonal weather data can be co-produced.

Key findings reported by UMFULA from work in Tanzania and Malawi include (FCFA, 2019a, p5):

- "Understanding the likely future characteristics of climate risk is a key component of adaptation and climate-resilient planning, but given future uncertainty it is important to design approaches that are strongly informed by local considerations and robust

\footnotetext{
${ }^{5}$ Policy-makers included: government, development partners and civil society.

6 "The pilot study focused on five practical adaptation decisions, which are relevant for the medium to long-term. These included: the mainstreaming of climate change into Rwanda's social protection programme; project appraisal of adaptation projects in the National Climate and Environment Fund (FONERWA); climate risk screening of hydro-electricity plants; resilience mainstreaming into agricultural development investment plans; and urban green growth/ resilience plans." (Watkiss, 2015b, p2)
}

${ }^{7}$ https://futureclimateafrica.org/project/umfula/ Accessed 23.4.21

${ }^{8}$ https://futureclimateafrica.org/summary-of-fcfas-research-on-climate-change-in-tanzania/ Accessed 23.4.21 
to uncertainty, i.e. options that work reasonably well across a range of uncertain future climate (and other) conditions.

- Choosing the right tools and approach for climate risk assessment and adaptation to suit the scale of the decision allows a suitable trade-off between robustness and resources required (time and expertise) for analysis.

- In the medium term, policy decisions require careful cross-sectoral planning, particularly in cases involving large investments, long life-times and irreversibility, where there is a strong argument for assessing resilience to future climate change (for example around water, energy and food in Malawi and Tanzania).

- The process of co-production of knowledge by researchers and wider stakeholders contributes to building societal and institutional capacity to factor climate risks into long-term planning. It also builds the capacity of researchers to better understand real world decision contexts in which climate change is one of many important factors."

Evaluation work on climate models is described. Factoring uncertainty into programming is highlighted but there is little on how this is being done or should be done. Modelling of future water availability in the Rufiji basin in Tanzania shows a range of different impacts from much higher flows to much lower flows (FCFA, 2019a). The report recommends coupling the hydrological system with a water resource system to incorporate into planning considerations. Stakeholder consultations across different sectors (in Tanzania, Malawi and Zambia) identified management objectives but how these consultations were run is not described. Policy incoherence was noted as a barrier to adaptation. Change in leadership and ministerial mandates makes it difficult for information transfers to have lasting impact. Reliance on donor funding is highlighted as an issue which undermines autonomy and agency to act among ministry staff. Supporting autonomy and operational budget to government staff is recommended to implement adaptation policy.

Research on how smallholder farmers access and use climate information was undertaken in the Kilombero River catchment of Tanzania (FCFA, 2019a). People were found to use seasonal forecasts from the country's national meteorological service to make decisions on water-use and season planting. They receive the information through television or radio broadcasts.

Collaboration, including workshops, are noted within a commitment to ensuring research findings have impact in case study countries. However, lessons on how to collaborate with stakeholders are not described.

UMFULA engaged university students through lectures and clinic sessions at Sokoine University of Agriculture and the University of Dar es Salaam. They also helped to facilitate the Africa Climate Leadership Programme (AfriCLP) in 2008. They participated in Africa Water Week and a number of open webinars. They were in contact with the Tanzania Met Agency to share findings on climate processes for the region. There are not details of how this sharing was facilitated or recommendations.

\section{Uganda}

FCFA work in Uganda is carried out by HyCRISTAL aiming to understand climate variability to support effective long-term decision-making. 
Information is being produced including an integrated resource for climate, crop, fisheries, and livelihoods information platform, Integrated Database for African Policymakers (IDAPS). ${ }^{9}$ Local stakeholders were introduced to climate information with simulations of surface water flooding under different climate scenarios. Then local groups talked about their lived experience of flooding to check the local relevance of the flood model. Modelling was translated into management tools by combining the data with sanitation, infrastructure and socioeconomic maps. Developing the model created opportunities for discussions between a range of stakeholders.

Discussions helped understand the complexity of the issue and an informational video shares the story. ${ }^{10}$ Visual story-telling was found to be successful in addressing the mismatch between the information provided to farmers and the information needed by farmers in the Mukono district of Uganda. ${ }^{11}$ Video was used to initiate a dialogue around the impacts of climate change on agriculture with local government officials. The farmers were able to secure increased agriculture extension funding for that financial year.

The IDAPS work was reported to be positively received by stakeholders such as the Kampala Capital City Authority and National Water and Sewerage Company. Lessons on the process were not identified other than these approaches were deemed successful.

In another example, HyCRISTAL were able to develop a strong working relationship with the Ugandan Ministry of Water and Environment (MWE) who were already developing catchment plans for Water Management Zones. Here HyCRISTAL were able to fit in with something the government were already working with which suggests a lesson for success. However, adoption of the model by the MWE is only 'assumed' and not certain. ${ }^{12}$

Engagement on changing lake levels were found to be successful following successive calls with stakeholders. The calls aided in building a common ground in understanding the needs and possibilities.

A summary of HyCRISTAL work in both Kenya and Uganda highlights approaches such as identifying on-the-ground partners for project uptake, co-production of decision-relevant climate information, taking a risk-based approach etc. but lessons on how to do this are not described (FCFA 2020). Recommendations / lessons for turning research into usable predictions include:

- understanding the processes that control user-relevant weather and past climate change

- understanding uncertainty in climate change from ensembles of global models and narrowing this through future-centric evaluation

\footnotetext{
${ }^{9}$ http://www.walker.ac.uk/research/projects/idaps-integrated-database-for-african-policy-makers/ accessed 27.4.21

${ }^{10} \mathrm{https}$ ://futureclimateafrica.org/summary-of-fcfas-research-on-climate-change-in-uganda/ accessed 27. 4. 21

${ }^{11}$ https://impact-relevance.futureclimateafrica.org/novel-approaches Accessed 23.4.21

${ }^{12} \mathrm{https}$ ://futureclimateafrica.org/summary-of-fcfas-research-on-climate-change-in-uganda/ accessed 27. 4. 21
} 
- further work on Coupled Model Intercomparison Project. ${ }^{13}$

\section{East Africa region scientific findings}

Key scientific findings from HyCRISTAL on the East African region (Finney et al, 2019):

- Larger and more wide-spread changes in extreme rainfall should be anticipated.

- Models show climate change is expected to lead to longer short rains, and an earlier end to long rains.

- Aerosol emissions may induce changes not addressed by modelling.

Burgin et al (2019) describe three possible futures with impacts for rural areas. It is narrated in a way that describes negative effects where adaptation is not in place, lessons are presented as warning and as incentive for good practice: "This is what is happening under this scenario for those who have adapted, this is what is happening for those that have not adapted. It would be useful to look at how this is being used in programming."

CP4-Africa modelling simulations with a new understanding of convection suggest extreme rainfall events (60mm in 1 hour) which occur every 30 years may happen as often as every 3-4 years by the end of the century. ${ }^{14}$

FCFA evaluation of climate models for Uganda discovered that models misrepresent the climate of Uganda (Kisembe et al, 2019). Models were found to present less rainfall than is currently observed.

A climate factsheet on East Africa describes how rising temperatures and changing rainfall will have implications for water availability; sanitation; livelihoods, including agriculture and fresh water fisheries; hydropower; and the potential for wind energy (see FCFA, 2016).

\section{FCFA across the whole of the African region}

\section{Co-production manual}

A manual advising on co-production identifies 10 principles for good co-production based on lessons learned (WISER \& FCFA, 2020):

1) Improve transparency of forecast accuracy and certainty

2) Tailor to context and decision

3) Deliver timely and sustainable service

4) Build trust

\footnotetext{
${ }^{13}$ See https://www.wcrp-climate.org/wgcm-cmip/wgcm-cmip6 for information on the Coupled Model Intercomparison Project

${ }^{14}$ https://impact-relevance.futureclimateafrica.org/step-changes Accessed 23.4.21
} 
5) Embrace diversity and respect difference

6) Enhance inclusivity

7) Keep flexible

8) Support conscious facilitation

9) Communicate in accessible ways

10) Ensure value-add for all involved

\section{Approaches to communicating climatic uncertainties with decision- makers}

Another guide makes recommendations on two communication formats: presentation of data using slide-sets, and stories about possible futures (2019b). Recommendations include:

- Visuals need to be presented by an individual with credibility and sufficient expertise

- Visuals need to be accompanied by clear written or verbal commentary

- Visual presentations need to be followed by tailored support to incorporate the information. For example, decision-makers requesting further information on specific areas.

- For narratives it is recommended to suggest three possible futures rather than use the language of uncertainty.

- Narratives are useful for exploring the implications of uncertainty and have been useful in finding a way forward to deal appropriately with the uncertainty.

- In some cases people feel like stories are not scientific enough. Narrative must be grounded in strong scientific evidence.

- Some felt the narratives were a very negative view of the future. The narratives must be explored to describe what a positive future would look like.

- People commonly question which future is more likely. Probabilities cannot be ascribed and the narrative that was most relevant and significant to the decision context should be chosen.

Guidelines for improving the communication of climate uncertainty include:

- Segment the target audience into meaningful groups and tailor communications to match audience characteristics.

- Use co-production to identify relevant questions through a series of engagements.

- Make sure the audience's level of vulnerability to weather and climate related impacts is explored at an early stage of engagement.

- Collaboration between scientists and stakeholders must discuss uncertainty openly and be meaningful in accordance with user needs. Discussion may discuss the source of uncertainty and will require reflection and review over time. 
- If resource constraints prevent face-to-face stakeholder meetings then co-production should be facilitated in other ways such as via templates, flow-charts, or decision trees. ${ }^{15}$

- Communications must be designed to enhance trust in the producers and communicators of information. For example showing their human side with photos and descriptions of their work. Establish a human connection.

- Ensure visuals are easy to comprehend. Guidelines include Harold et al. (2017).

- Evaluate communication effectiveness.

\section{Critical reflection on programme learning}

Interviews and survey with FCFA project staff identified learning in three areas: 1) collective learning in FCFA, 2) leadership and capacity development, and 3) knowledge co-production and research uptake (FCFA, 2020b).

Facilitated learning processes deemed most impactful by participants involved in-person engagement and 'expert facilitation'. Barriers that prevent Southern partners from taking on positions of leadership are identified including issues of capacity. Capacity building efforts seem to have a short institutional legacy.

Challenges in research uptake was identified where decision-maker demand was limited. Information needed to be tailored to their needs and building their capacity to interpret information. The report suggests that it is likely too early to assess the impacts of knowledge mobilisation within FCFA but that an expanded focus on assessing and comparing knowledge brokering outcomes and impacts is needed.

Recommendations on research and knowledge mobilisation practice suggests greater impact may require a shift in the way research is practised. Move towards in-person co-production is recommended. Innovation in the field of designing and facilitating virtual engagements is needed to manage engagement within resource constraints.

\section{How collective learning can promote the uptake and use of climate research}

A brief on collective learning across FCFA projects defines it as "learning which emerges from activities of knowledge sharing, collaboration and co-production processes“ (Araujo et al, 2020, p1). Collective learning is supported by good facilitation and can lead to discovery of novel approaches to facilitate engagements that effectively promote uptake and use of information. Promoting uptake and use should focus on the needs of the user and focus on co-production processes which allow for ongoing dialogue and innovation.

\footnotetext{
${ }^{15}$ How templates, flow-charts or decision trees work in these situations is not outlined and requires further research.
} 


\section{WISER learning event}

Weather and Climate Services for Africa (WISER) aims to improve the quality, accessibility and use of weather and climate information services at all levels of decision making for sustainable development in Africa. WISER held a number of learning events which gathered participants from different projects to share experience and lessons. A short webinar distilled top-level findings from the regional events. Recommendations were identified in 6 areas: 1) Ring-fence an inception phase to ensure relevant planning; 2) Follow a co-production approach to address the barriers to gender equity and inclusion; 3 ) Build and sustain capacity across all project levels; 4) Enhance synergies between projects to help replicability and uptake of climate services; 5) Facilitate stakeholder dialogue and iterative climate service processes that enable and address feedback; and 6) Sustainability. Recommendations were generalised across the region and projects.

Recommendations relevant for this report on approaches include:

- It is important to connect with senior staff from national weather agencies during project inception and their broader strategies and plans to lock into national frameworks for climate services.

- Gender and disability inclusion should be explicitly included in plans and have resource allocation.

- Programmes should be learning from each other with regards to linking science and economic opportunity.

- Institutional and partner knowledge should be built upon and different ways of delivering should be shared.

- Projects should invest in relationship building with other projects from the start to effectively utilise experience. Stakeholder/landscape analysis of national and regional focus points can support sharing.

- Learning between and among projects needs to be planned and integrated into project activities. The learning event had been very valuable and should continue. Mechanisms for sharing experience and learning from methodologies, technologies, and challenges etc. are needed. And should be integrated into project design.

- Stakeholder dialogue and iterative climate service processes need to be facilitated that enable and address feedback.

- User feedback loops require dedicated human resources. Appropriate roles and responsibilities including staff with stakeholder engagement and adaptive management in their job description.

- Co-production was agreed to pay-off but that there is room for improvement and future initiatives should plan for even more and regular stakeholder engagement.

\section{References}

Araujo, J., Bouwer, R., Carter, S., Graham, R., Harvey, B., Huang, Y., Marsham, J., Rouhard, E., Vincent, K. (2020). How collective learning can promote the uptake and use of climate research. 
Brief, Cape Town: Future Climate for Africa. https://futureclimateafrica.org/wpcontent/uploads/2020/11/FCFA_Collective_Learning_Brief_2020.pdf

Burgin, L., Walker, G., Cornforth, R., Rowell, D., Marsham, J., Semazzi, F., ... \& Wainwright, C. (2019). Possible futures for rural East Africa under a changing climate: HyCRISTAL climate narrative rural infographic and Brief. https://zenodo.org/record/3620757\#.YIE3uehKg2z

Bouwer, R. \& Araujo, J. (2020). Summary of FCFA work in Rwanda.

https://futureclimateafrica.org/wp-content/uploads/2020/05/fcfa_country_summary_rwanda.pdf

Finney, D., Marsham, J., Rowell, D., Way, C., Evans, B., Cornforth, R., ... \& Xia, S. (2019).

Scientific Understanding of East African climate change from the HyCRISTAL project.

https://futureclimateafrica.org/wp-content/uploads/2019/10/hycristal_climate_summary_v1.pdf

FCFA (2020). HyCRISTAL: Integrating Hydro-Climate Science into Policy Decisions for Climate-

Resilient Infrastructure and Livelihoods in Africa. https://futureclimateafrica.org/wp-

content/uploads/2020/06/fcfa_rc_summary_hycristal.pdf

FCFA (2020b). A critical reflection on learning from the FCFA programme. Climate and

Development Knowledge Network and Future Climate for Africa.

https://futureclimateafrica.org/wp-content/uploads/2020/11/FCFA-Learning-report.pdf

FCFA (2019a). The current and future climate of central and southern Africa What we have learnt and what it means for decision-making in Malawi and Tanzania.

https://futureclimateafrica.org/wp-content/uploads/2019/10/key-messages-from-the-umfulaproject.pdf

FCFA (2019b). Approaches to communicating climatic uncertainties with decision-makers. https://futureclimateafrica.org/wp-content/uploads/2019/09/approaches-to-communicatingclimatic-uncertainties-with-decision-makers_final.pdf

FCFA (2016). Africa's climate helping decision-makers make sense of climate information. https://futureclimateafrica.org/wp-content/uploads/2016/11/africas-climate-final-report-4nov16.pdf

FONERWA (2018). FONERWA climate risk screening tool. https://futureclimateafrica.org/wpcontent/uploads/2018/09/fonerwa-climate-risk-screening-tool.pdf

Harold, J., Lorenzoni, I., Coventry, K. R., \& Minns, A. (2017). Enhancing the accessibility of climate change data visuals: Recommendations to the IPCC and guidance for researchers. Report published by the Tyndall Centre for Climate Change Research, Norwich, UK http://guidance.climatesciencecognition.com/

Kisembe, J., Favre, A., Dosio, A., Lennard, C., Sabiiti, G., \& Nimusiima, A. (2019). Evaluation of rainfall simulations over Uganda in CORDEX regional climate models. Theoretical and Applied Climatology, 137(1), 1117-1134. https://link.springer.com/article/10.1007/s00704-018-2643-x

Walker, D. P., Birch, C. E., Marsham, J. H., Scaife, A. A., Graham, R. J., \& Segele, Z. T. (2019). Skill of dynamical and GHACOF consensus seasonal forecasts of East African rainfall. Climate Dynamics, 53(7), 4911-4935. https://link.springer.com/article/10.1007/s00382-019-04835-9 
Watkiss, P. (2015a). Mainstreaming climate information into sector development plans: the case of Rwanda's tea and coffee sectors. Climate and Development Knowledge Network.

https://futureclimateafrica.org/wp-content/uploads/2016/01/Paul-Watkiss-report-Rwanda.pdf

Watkiss, P. (2015b). Using climate information to achieve long-term development objectives in Rwanda. Climate and Development Knowledge Network. https://futureclimateafrica.org/wpcontent/uploads/2015/02/FCFA_PolicyBrief_Rwanda_.pdf

WISER \& FCFA (2019). Co-production in African weather and climate services, Manual. https://futureclimateafrica.org/wp-content/uploads/2020/10/WISER-FCFA-coproductionmanual.pdf

\section{Suggested citation}

Bolton, L. (2021). Lessons for FCDO climate change programming in East Africa. K4D Helpdesk Report 998. Brighton, UK: Institute of Development Studies. DOI: 10.19088/K4D.2021.085

\section{About this report}

This report is based on six days of desk-based research. The K4D research helpdesk provides rapid syntheses of a selection of recent relevant literature and international expert thinking in response to specific questions relating to international development. For any enquiries, contact helpdesk@k4d.info.

K4D services are provided by a consortium of leading organisations working in international development, led by the Institute of Development Studies (IDS), with Education Development Trust, Itad, University of Leeds Nuffield Centre for International Health and Development, Liverpool School of Tropical Medicine (LSTM), University of Birmingham International Development Department (IDD) and the University of Manchester Humanitarian and Conflict Response Institute (HCRI).

This report was prepared for the UK Government's Foreign, Commonwealth and Development Office (FCDO) and its partners in support of pro-poor programmes. Except where otherwise stated, it is licensed for non-commercial purposes under the terms of the Open Government License v3.0. K4D cannot be held responsible for errors, omissions or any consequences arising from the use of information contained in this report. Any views and opinions expressed do not necessarily reflect those of FCDO, K4D or any other contributing organisation.

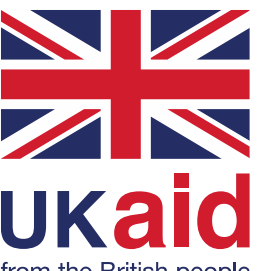

(C) Crown copyright 2021. 